\title{
Contract cheating will erode trust in science
}

\section{To combat academic dishonesty, focus on educational systems and not just individual offenders, says Tracey Bretag.}

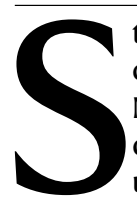
tories of students paying others to do their work come from all around the world. In the 2015 MyMaster scandal in Australia, hundreds of students who were enrolled in more than a dozen universities paid a total of at least Aus $\$ 160,000$ (US $\$ 108,000)$ to a 'service' that provided ghost-written essays and responses to online tests. In 2018, YouTube stars on more than 250 channels received money for promoting a cheating service called EduBirdie. Similar companies have been uncovered in the United States and elsewhere. Scientists should not deceive themselves: they are not immune.

Academics call this 'contract cheating'. My colleagues and I have assembled what is, to our knowledge, the largest data set on the topic - with responses from some 14,000 students and 1,000 teachers across 8 Australian universities. We found that roughly $6 \%$ of students have engaged in the practice; that most who cheat do so more than once; and that both post- and undergraduate students engage in it. Cheating is not new, but the proliferation of commercial, online services in the past 5-10 years has made it easier than ever.

And cheating is becoming increasingly normal. Since the 1990s, universities around the world have reimagined themselves as commercial enterprises that promote educational 'products' to student 'consumers'. In 2017, a commentator likened the brash marketing strategies of some UK universities to the advertising of shampoo, and hundreds of academic papers have openly criticized the 'marketization' of higher education. It's no wonder students opt to take the most convenient route to an academic credential - just as they would shop around for any other deal. In our survey, more than one-third of teachers specifically blamed contract cheating on the commercialization of higher education.

Data from student surveys uncovered three factors associated with contract cheating: speaking English as a second language; thinking that there are lots of opportunities to cheat; and dissatisfaction with the educational environment. Two trends - dwindling teaching resources and lower linguistic and academic standards for admission - contribute to the situation. And although little research has been done on the frequency of this phenomenon in scientific researchers, those driven to outsource their written work as undergraduates will probably be tempted to do so as academics under pressure to 'publish or perish'.

A cursory Google search for 'ghost-writing services for researchers' identifies thousands of services offering complete dissertations, grant applications, conference papers and journal articles. Outfits selling authorship on research

\section{$\Lambda$ \\ Scientists should not deceive themselves: they are not immune."}

Tracey Bretag is an associate professor in the School of Management at the University of South Australia in Adelaide. e-mail: tracey.

bretag@unisa.edu.au publications have been uncovered in China and Iran, and the market for ghost-written $\mathrm{PhD}$ dissertations is reportedly booming in Ukraine and seems healthy in Australia.

We need to recognize that contract cheating is not just the responsibility of individual students, teachers or institutions. It is a systemic issue. Government funding agencies, regulatory authorities and leaders in higher education must tackle it.

Some have made a good start. In 2018, New Zealand successfully prosecuted commercial cheating service Assignments4U, which paid NZ\$2.1 million (US\$1.3 million) in an out-of-court settlement and closed down. In April 2019, the Australian Department of Education introduced a draft bill targeting commercial services that advertise or provide unauthorized assistance to students. It is expected to become law next year. Ireland has a similar law on its books. Such laws send a clear message. Cheating is not just unethical, it is illegal - and it has consequences. Laws hold accountable the stakeholders that are essential for contract cheating over which educational institutions have no control.

I feel that another important strategy is to reduce demand from within. Our team has found shockingly little concern in academics, including cheating students, non-cheating students and senior decision makers. They think that cheaters are just hurting themselves and are not damaging the community.

A radical shift in rhetoric would help individuals see the value of actually doing their work. Institutions need to stop treating education as a product and refrain from determining the value of research by the amount of funding received or the number of papers produced. Instead, they should focus on building academic cultures that are committed to integrity and that place abiding faith in the value of knowledge creation.

We cannot simply tell people not to cheat. We must provide support so that students feel capable of completing their assignments. That includes ensuring that institutions have appropriate language requirements for admission and allocating appropriate resources for teaching and learning.

Contract cheating is also a threat to public safety. It is not difficult to imagine how doctors, engineers and social workers who have outsourced their learning could pose a risk. This practice even threatens the common understanding of scientific facts - a big concern in the 'fake news' age. A large number of researchers purchasing their theses, publications and qualifications would endanger the credibility of science.

To defend itself, the scientific community must recognize that contract cheating is not an isolated problem caused by 'bad apples'. It is an attack on core academic values that necessitates stronger leadership from government departments, funders, regulators and educational institutions. This threat requires a collective response. 